Białoruski Uniwersytet Państwowy

informatyki i radioelektroniki, Mińsk

https://orcid.org/0000-0002-1157-4806

\title{
Семантический аспект понятия дом в готической литературе и его трансформация в прозе Говарда Филлипса Лавкрафта
}

Готическая литература без сомнения оказывает мощное воздействие на читателя любой эпохи. Готика одновременно и пугает, и притягивает своей возможностью поколебать его уверенность в реальности. Готическая проза открывает перед читателем целый ряд ужасов из повседневной жизни: таинство смерти, боль утраты, непредсказуемые зигзаги самой жизни. Эта литература способна отразить скрытый ужас повседневности, заострить внимание на будничных незначительных фактах и событиях, преувеличив их настолько, чтобы максимального ошеломить читателя. Парадокс ее воздействия в том, что читатель при полном отсутствии реальной опасности способен испытывать ощущения крайней тревоги и беспокойства.

Топос дома играет важную роль в готическом произведении и выполняет двойную функцию: с одной стороны - это пространство, где разворачиваются пугающие сверхъестественные события, с другой, дом есть пространство быта, насыщенное различными артефактами, через которые зачастую и осушествляется связь с прошлым и сферой ирреального.

Исследователь Э.Р. Курциус определяет топосы как твердые клише или схемы мысли и выражения, запечатлевающие формуль, фразы, оборотьи, иитатыл, стереотипнье образы, эмблемьл, унаследованные мотивы ${ }^{1}$. Словарь иностранных слов трактует топосы следующим об-

1 Цит. за: Е. В. Крикливец, Художественный мир В. Астафьева и В. Козько: специфика пространственно-временной организачии, Витебск 2014, с. 17. 
разом: Tопос, mon [гр. topos - место, околича] - ритор., лит., перен. общее место, элементарный тематико-стилистический образеи, литературный шаблон, риторическая схема, общепринятое суждение, устойчивая языковая фигура, речевая формула.

Следует отметить, что топос и хронотоп тесно переплетены. Топос - это не только конкретное место действия, но и авторский образ, несущий определенную эмоциональную нагрузку. Топос неразрывно связан не только с текстом, но и с пространством культуры и, как полагает Э.Р. Курциус, выступает как архетип.

Тема дома, семьи, семейной истории - одна из ключевых в мировой литературе. Готическая литературная традиция в этом плане не является исключением, ведь образ замка/дома выступает в ней одним из основополагающих элементов. Важнейшим компонентом в готической традиции принято считать «проклятое место», где происходит столкновение реального и сверхъестественного. В замках и родовых поместьях разворачиваются драматические события и решаются судьбы их гостей и обитателей, пространство замков, как правило, насыщено богатой символикой. Замок выступает в готической литературе как смыслообразующий и структурообразующий компонент сюжета, именно в замке герой находится во власти сверхъестественных сил, лицом к лицу со своей судьбой.

Важная особенность готического замка заключается в том, что он способствует погружению в другие временные пласты, в тайную историю дома и семьи через физические или психологические феномены (сны, галлюцинации, спиритические сеансы), которые происходят внутри дома. Литературовед Дэвид Пантер полагает, что отношение к прошлому у готики есть соединение отталкивания и притяжения, страх перед насилием прошлого и его силой над настоящим, и в то же время тоска по многим качествам, которыми это прошлое обла$\partial а л 0^{3}$. Пространство замка имеет специфический хронотоп, потому что способно выступать в качестве проводника для транслирования событий тревожного прошлого в не менее тревожное настоящее. Готический нарратив несет в себе гнет прошлого, прорывающегося сквозь замкнутое пространство, что усиливает настроения клаустрофобии, упадка и распада.

2 Н. Г. Комлев, Tопос, mon, [в:] Словарь иностранных слов, [online], http://rusyaz.niv.ru/doc/foreign-words-komlev/fc/slovar-210.htm\#zag-2276, [доступ: 02.02.2021].

3 D. Punter, The literature of terror: a history of Gothic fictions from 1765 to the present day, Vol. 2: The modern Gothic, London; New York 1996, p. 198. 
Дом служит укрытием человеку, дарит тепло и стабильность, дом символизирует оседлый образ жизни, а также выступает границей между пространствами - человеческий быт и природа, Свое-Чужое. В готической традиции дом выступает местом столкновения мира реального и ирреального.

В трактовке ужасного представители готической литературы опираются на трактат Эдмунда Бёрка «Философское исследование о происхождении наших идей возвышенного и прекрасного» (1756), который оказал значительное влияние на готическую литературу. Дом в общемировой культуре - это не только строение, с домом связаны семья, история рода. Поэтому художественная литература в целом и готическая литература в частности часто используют этот мотив как связующее звено между домом и историей семьи (Х. Уолпол «Замок Отранто, Э.А. По «Падение Дома Ашеров», Н. Готорн «Дом о Семи фронтонах»).

Более того необходимо отметить, что дома могут иметь «характер», и человек эмоционально и интеллектуально реагируют на окружающее пространство. Так, исследователь А. Холгейт отмечает: Tom факт, что мы все в некоторой степени испьтывваем чувства клаустрофобии и агорафобии четко указывает, как пространство может влиять на нас (...) Такие чувства очень часто проецируются на неодушевленные предметьи ${ }^{4}$.

Кроме того, А. Холгейт обращает внимание на тот факт, что при переходе из одного пространство в другое чувства также меняются. Перемещение в пространстве вызывает у человека разные эмоции. Под воздействием различных факторов чувства могут быть как приятными, так и неприятными. Если возникает препятствие воображаемому или реальному движению, человек испытывает негативные эмоции. Поэтому пространство дома не статично, а динамично. Древнеанглийские слова, обозначающее «дом» (hus), и «кожа»/«шкура» $(h y d)^{5}$ имеют один корень. Это указывает на потенциальную возможность термина символизировать одновременно мертвую и живую органическую материю.

Дом обычно ассоциируется с безопасностью и стабильностью. С другой стороны, безопасность может быть иллюзорна и легко разрушена. Природный инстинкт заставляет человека воспринимать дом как убежище, но дом зачастую скрывает и тайны прошлого. В таком

4 A. Holgate, Aesthetics of Built Form, Oxford 1992, p. 90.

5 House, [в:] Online etymology dictionary, [online], https://www.etymonline.com/word/ house, [доступ: 09.02.2021]. 
случае дом с привидениями становится враждебным пространством, вызывает противоречивые чувства и порождает ложное чувство безопасности. Место действия в готическом романе - замок или аббатство с богатой историей. События, некогда произошедшие в этих местах, влияют на судьбы героев, которые там обитают. Например, место дейсвия в романе Х. Уолпола «Замок Отранто»- готический замок в Италии со своими тайнами. В романах английской писательницы А. Радклиф, которая наследует опыт Х. Уолпола, также присутствуют готический замок, сверхъестественные элементы, таинственные шорохи и звуки. Отличительной чертой ее произведений является сгущение красок, нагнетание атмосферы ужасного, обостренное предчувствие беды.

Готическая проза давала писателям простор для импровизации. Унаследовав от XVIII века открьтость структурьл, - отмечает H. Соловьева, - готический роман явился экспериментальньм жанром 6 . Одной из существенных особенностей готического романа является открытость границ жанра, что позволяло писателям экспериментировать и тем самым способствовало появлению нового вида литературы - готической. Хотя романы, которые принято относить к готическим, а также произведения, впитавшие готические традиции и называемые «готикой», объединены некоторыми тематическими и стилистическими признаками. Тем не менее они все же сильно различаются как в плане эмоционального воздействия на читателя, так и читательской реакцией на текст. Термин готика скорее применим к тем произведениям, в которых сверхъестественное вступает в конфликт с реальностью. Несмотря на шаблонный и условный характер готического романа, на такие типичные элементы и эффекты, как готический замок (дом) с призраками, злодеи, мрачные пейзажи, сумасшествие героев, страх и ужас, этот жанр романа остается чрезвычайно пластичным.

По мере эволюции жанра события стали разворачиваться в монастырях, на кладбищах, в фамильных особняках, соборах, домах и квартирах. Неизменным остается лишь тот факт, что герой находится во власти сверхъестественных сил, лицом к лицу со своей судьбой в замкнутом пространстве. Таким образом, готический роман имеет особый хронотоп. Не только пространство, но и время играют существенную роль в готическом произведении, поскольку прошлое через место действия влияет на настоящее и будущее героев.

6 Н. Соловьева, В лабиринте фантазии, [в:] Комната с гобеленами: английская готическая проза, Москва 1991, с. 13. 
Развитие литературы ужасов в США происходило иначе, чем в Европе, оно неразрывно связано с историей и культурой молодой нации, а также с литературными тенденциями того времени. Первоисточником сюжетов для эмигрантов, гонимых из Европы охотой на ведьм и религиозными войнами, социально-бытовыми трудностями, служила новая среда, которую им предстояло осваивать, сказалось также влияние европейского готического романа.

В литературе США XIX века из готического романа (Ч. Брокден Браун, А. Митчел) американская готика приходит в жанр новеллы (Э. По, В. Ирвинг, А Бирс). Например, литературный ужас Э.А. По приобретает новые черты: за счет гармонического синтеза художественного и научного подходов он становится более естественным и в то же время агрессивно насыщенным, чем существенно отличается от ужаса в европейском готическом романе. В прозе Э.А. По об ужасном выделяют произведения, связанные с проявлением деформированной психики героя, и рассказы, в которых ужас вызывается сверхъестественными силами.

Американский писатель Говард Филлипс Лавкрафт (1890-1937) внес свой вклад в трансформацию готической традиции. Писатель пришел в литературу в эпоху бурного развития научных знаний и космических открытий, что не могло не повлиять на его творческий путь. Он понимал, что человек, открывая пространство космоса, изучает его и в то же время испытывает страх. Г.Ф. Лавкрафт в своих произведениях создал оригинальную авторскую мифологию, которую литературоведы называют «Миф Ктулху». В рассказах из цикла «Мифов Ктулху» писатель сосредоточился на создании атмосферы сверхъестественного ужаса, который приходит из неведомого пространства и обрушивается на человека. Таким образом художник подверг трансформации как топос дома, так и другие типичные элементы, свойственные готической литературе.

В рассказе «Сны в ведьмином доме» (1933) действие происходит в Новой Англии в вымышленном городе Аркхэм, но при этом писатель упоминает исторические факты о Салемском процессе над ведьмами и конкретные исторические фигуры. Ведьма Кеция Мейсон обладает присущими ведьме чертами: она изображается дряхлой старухой, ей прислуживает крыса с человеческим лицом. Людские жертвоприношения, существование Черного Человека, мотив сделки с дьяволом (Джилмен расписывается кровью в книге Черного человека) и страх ведьмы перед распятием вызывают у читателя ассоциации с народными поверьями и историями о чудовищных вампирах. В то же время 
Черный Человек у писателя приравнен к божествам лавкрафтовского пантеона, а на ведьмином шабаше произносятся заклинания из вымышленного «Некрономикона». Использование такого рода сочетаний классических элементов готического повествования с одной стороны и фигур из собственно авторской фантастической вселенной с другой позволило американскому художнику слова Г.Ф. Лавкрафту создать аутентичные произведения, балансирующие на грани иллюзии и реальности.

С самого начала повествования автор дает понять читателю, что страшные события, которые произойдут с Уолтером Джилменом, будут связаны с домом, где поселился герой, потому что страх исходит именно от древнего дома, что издавна просльл в округе нечи$c_{\text {cmbl }}{ }^{7}$. Комната Джилмена имеет странную геометрию и скрытые пространства, что указывает на ее необычность. Гипердетальные описания только усиливают напряжение в рассказе:

...северная ее стена имела явный наклон внутрь, к северу же был скошен и низкий потолок. В наклонной стене Джилмен обнаружил небольшое отверстие с неровными краями - несомненно, ход в крысиную нору - и еще несколько таких же отверстий, но уже тщательно заделанных; отсутствовали малейшие признаки того, что имеется - или хотя бы имелся ранее - какой-нибудь доступ в пространство между наклонной стеной комнаты и совершенно прямой внешней стеной здания: взглянув на дом снаружи, легко было убедиться, что там когда-то имелось и окно, заложенное, впрочем, уже очень давно. Также совершенно недоступной оказалась и та часть чердака, которая находилась над комнатой Джилмена и определенно должна была иметь наклонный пол. (...)

С течением времени интерес Джилмена к тому, что могли скрывать необычная стена и потолок его новой комнаты, только возрастал - он начал думать, что величина угла между ними может иметь некий математический смысл, дающий ключ к разгадке того, для чего они были предназначены ${ }^{8}$.

Геометрическая составляющая рассказа - это яркий пример влияния творчаства Э.А. По.

Необычная конфигурация комнаты становится вратами в мир параллельной реальности, помещение оказывает на героя гипнотическое воздействие. Идея неправильного пространства комнаты важна для лавкрафтовской концепции «плохого места», которое обостряет тревожные ощущения главного героя:

7 Г. Ф. Лавкрафт, Сны в ведьмином доме, [в:] Полн. собр. соч., т. 1: Затаившийся страх, Москва 1992, с. 171.

8 Там же, с. 175 . 
Очевидно, в течение всего времени, что Джилмен жил в комнате, необыкновенная ее форма оказывала на него в высшей степени странное, едва ли не гипнотическое воздействие: в ту холодную блеклую зиму он то и дело ловил себя на том, что все пристальнее вглядывается в линию, соединяющую наклонную стену и скошенный потолок. Примерно в то же время он стал ощущать и растущее беспокойство по поводу обнаружившейся вдруг полной неспособности сконцентрироваться на изучаемых дисциплинах - беспокойство тем более оправданное, что приближался срок очередных экзаменов. С другой стороны, чуть меньше давал себя знать невероятно обострившийся слух. Однако, несмотря на это последнее обстоятельство, жизнь Джилмена превратилась в навязчивую и почти непереносимую какофонию; но самым ужасным было неослабевающее ощущение, что в этом хаосе присутствуют новые, неслыханные доселе звуки они находились где-то у самой границы восприятия, быть может, имея источник вне пределов постигаемого ${ }^{9}$.

Г.Ф. Лавкрафт часто упоминает в своих произведениях примеры неэвклидовой геометрии, когда другие пространства и измерения не подчиняются законам привычного человеку мира, поэтому неправильная геометрия приводит героев в ужас своим хаосом и беспорядочностью. Стивен Кинг пишет: Он [Г.Ф. Лавкрафт - E.T.] nucaл, что одних размышлений о таких вещах достаточно, чтобы свести человека с ума. Он был недалек от истины: из различных психологических экспериментов мы знаем, что, вмешиваясь в восприятие человеком перспективы реального мира, мы затрагиваем самые основы человеческого мозга $a^{10}$.

Г.Ф. Лавкрафт, проживший большую часть своей жизни в Провиденсе (штат Род-Айленд), широко использует историю предков этого региона и феномен дома подвергает существенной трансформации. «Проклятым местом» становятся заброшенные фермерские дома, а зачастую даже целые города и поселки («Хребты безумия», «Шепоты во мраке», «Сияние извне», «Тень над Инсмутом»). В реалистические пейзажи Новой Англии писатель помещает космические чудовища, создавая тем самым вымышленные города с их темными сторонами новоанглийской истории.

В готической традиции одним из ключевых моментов выступает место действия, т. е. населенный призраками дом, замкнутое пространство которого довлеет над героями и сводит их с ума. В произведениях

9 Г. Ф. Лавкрафт, Сны в ведьмином доме, [в:] Полн. собр. соч., т. 1, Затаившийся страх, Москва 1992, с. 176.

10 С. Кинг, Пляска смерти, Москва 2018, с. 98. 
Г.Ф. Лавкрафта ужас приходит извне, из враждебного человеку космического пространства, что способствует расширению топоса ужаса. Таким образом, Г.Ф. Лавкртафта, как полагает Фэй Рингел, можно назвать пионером готической научной фантастики ${ }^{11}$.

Наука XX века открыла миру бездны бескрайнего космоса (теория А. Эйнштейна о бесконечности Вселенной), который американский писатель превращает в источник леденящего душу ужаса. Г.Ф. Лавкрафт бережно собирает новоанглийские легенды, предания и пытается укоренить в них свой миф о существовании неведомых миров и существ. Например, в рассказе «Шепоты во мраке» (1931) лавкрафтовские чудовища напрямую связаны с индейскими легендами:

Старинные предания, несмотря на их туманность и расплывчатость, отличались крайним своеобразием и, судя по всему, претерпели влияние со стороны еще более древних индейских легенд. И хотя я никогда не был в Вермонте, мне это было прекрасно известно, ибо в свое время я ознакомился с уникальной монографией Эли Давенпорта, в которой были представлены истории, собранные до 1839 года и записанные со слов самых старых жителей штата. Кроме того, этот материал во многом совпадал с тем, что я лично слышал от сельских старожилов в горах Нью-Гэмпшира. Во всех этих историях содержались намеки на некое тайное племя чудовищ, скрывающееся в недоступных горных уголках - среди непроходимых лесов и темных лощин, где из неведомых источников берут свое начало реки ${ }^{12}$.

Рассказчик противопоставляет Новую Англию внешнему миру, он ностальгирует по прошлому, но при этом замечает, что этот уголок Америки претерпел незначительные изменения: Поезд мчал меня в глухой уголок Новой Англии, донельзя провинциальный и патриархальный по сравнению с охваченными техническим прогрессом побережьем и южными районами, где прошла вся моя жизнь. Передо мной разворачивалась девственная Новая Англия, земля моих предков - без инородчев, фабричного дыма, рекламньх шитов и бетонньх дорог. Современная жизнь почти не коснулась этих мест ${ }^{13}$.

В произведениях Г.Ф. Лавкрафта часто встречается ретроспекция, герои писателя погружаются в воспоминания о прошлом, отправляются в путешествия, и зачастую их временное перемещение совпадает с пространственным. Приезд мистера Уилмарта (он же рассказчик)

11 F. Ringel, I am providence: H. P. Lovecraft, [online], http://www.blackwellreference. com/public/tocnode?id=g9780470671870_chunk_g978047067187021, [доступ: 09.02.2021] 12 Г. Ф. Лавкрафт, Шепоты во мраке, [в:] Локон медузы, Тольятти; Екатеринбург 1993, с. 278.

13 Там же, с. 323. 
в глухие места Новой Англии переносит его в прошлое («Шепоты во мраке»). Герой по совету проводника переводит на часах время вспять: ... потому что в этих северных горных районах новомодное летнее время не действует. Я последовал его совету, повернув время вспять, казалось, не на час, а на век ${ }^{14}$.

Семантику перемещения героя во времени и пространстве отражает топос дороги в данном рассказе. Когда топос дороги динамичен, топос дома - статичен. В структуре хронотопа художественного произведения топос дороги раскрывает роль и место человека в мире. Перемещение героя во времени и пространстве подчинено идейной концепции автора и тесно связано с теми знаниями, которые предстоит открыть для себя герою-рассказчику. Повествователь предстает перед нами человеком рациональным, его знания основываются на опыте и фактах, он скептически относится к суевериям. Прибыв в глухую местность к своему знакомому мистеру Эйкли, рассказчик становится свидетелем страшных событий, которые существенно меняют его взгляды на мир.

Движение/перемещение в произведениях Г.Ф. Лавкрафта, как правило, всегда заводит героев в тупик: они либо погибают, либо сходят с ума от страшных тайн, что им открылись. Таким образом, путь/дорога героев связана с границей между жизнью и смертью, привычным миром и миром сверхъестественного. Спуск в ад («Кошмар в Ред-Хуке»), приезд в глушь («Шепоты во мраке») существенно трансформирует внутренний мир героев, их отношение к жизни.

Безусловно, символический перевод стрелок на часах словно обрывает связь рассказчика с миром настоящего, поезд мчит его за границу реальности на встречу с космическими чудовищами. Величественное описание природы, поросшая травой железнодорожная колея как символ победы природы над цивилизацией и символ статичности времени, ощущение тревоги свидетельствуют о полной изоляции и пробуждают фантазию героя:

Местность вокруг становилась все более глухой и безлюдной. Через горные ущелья тянулись старинные крытые мосты, а по берегу реки пролегала полузаросшая кустарником железнодорожная колея, которая подчеркивала присущую здешним местам атмосферу запустения. Временами горный пейзаж оживляли поражающие своей живописностью долины, зажатые в тиски крутых утесов, на чьих вершинах сквозь травянистое покрытие проступал сурово-серый гранит - девственный фундамент Новой

14 Там же, с. 323. 
Англии. Горные потоки, с необузданной силой перескакивая через встречающиеся на пути пороги, стремились к реке, унося с собой древние тайны недоступных пиков. То здесь, то там от дороги разбегались узкие, наполовину скрытые от глаз тропинки, ведущие куда-то сквозь величественные, стеной стоявшие леса, где под сенью вековых деревьев наверняка до сих пор скрываются полчища первобытных духов. Я озирался вокруг и думал: ведь Эйкли ездил по этой самой дороге, и именно здесь его донимали невидимые за стеною леса существа. (...) От близости здешних гор - уже не остроконечных, но скорее куполообразных - буквально захватывало дух. Они оказались гораздо круче и отвеснее, чем я себе представлял со слов других, и не имели ничего общего с известным мне обыденным миром. В покрывавших их склоны густых лесах, где не ступала нога человека, казалось, затаилось нечто невиданное и неслыханное; и даже в самом очертании хребтов чудилось какое-то непонятное, забытое за давностью лет послание, написанное гигантскими иероглифами во времена некой цивилизации исполинов, расцвет которой могут наблюдать в своих снах лишь редкие провидцы. В моей памяти разом встали все предания и ошеломляющие выводы, сделанные мною на основании вещественных доказательств и писем Эйкли, и от этого тягостное ощущение надвигающейся опасности стало еще сильнее. Похолодев изнутри, я вдруг осознал, зачем, собственно, приехал сюда и какие страшные, из ряда вон выходящие события того потребовали. В этот момент страх почти пересилил мою жажду проникнуть в тайну пришельцев ${ }^{15}$.

Герой рассказа, передавая свои ощущения, понимает, что время в этой глухой местности словно остановилось и осталось где-то там позади, за одним из поворотов пути. Дом господина Эйкли как архитектурное сооружение не вызывает страха, это был характерный для той местности типичный двухэтажный белый особняк. Чувство страха вызывает у героя сама местность:

Специально для меня дверь осталась распахнутой; но, прежде чем приблизиться и войти, я окинул все вокруг пристальным взглядом, пытаясь понять, что же поразило меня в этой картине мирной сельской жизни? Навесы и постройки были в полном порядке и ничем особо не выделялись, а старенький «форд», как ему и было положено, выглядывал из просторного, незапертого гаража. И тут я понял, в чем была загвоздка. Тишина. Полнейшая тишина. Обычно на ферме раздаются хотя бы приглушенные звуки - какой-нибудь клекот, свиное похрюкивание и так далее; здесь же никто не подавал никаких признаков жизни ${ }^{16}$.

15 Г. Ф. Лавкрафт, Шепоты во мраке, [в:] Локон медузы, Тольятти; Екатеринбург 1993, c. 326.

16 Там же, с. 331. 
Рассказчика, переступившего порог дома и отрезанного от внешнего мира, переполняет чувство тревоги, его сознание фиксирует странный запах. Хозяин дома Эйкли посвящает гостя в тайны неземных существ, говорит о возможности путешествовать во времени и пространстве. В данном рассказе Г.Ф. Лавкрафт вслед за Э.А. По развивает теорию американского ученого Дж. Симмса о существовании полостей в земной коре и о существовании иного мира. Посетителю дома сообщают, что здесь, в горах Вермонта, есть полости, которые ведут в огромные миры с неведомой нам жизнью: в залитый голубым светом К'ньян, озаренньй багрянием Йот и погруженный во мрак Н'кай. Именно оттуда, из Н'кая и появилось чудовище Цхатоггуа, то самое бесборменное жабоподобное божество, о котором упоминается в «Пнакотических рукописях», «Некрономиконе» и мифологическом иикле «Коммориом», которьй сохранил для потомков Кларкаш Тон - главный жреи Атлантидьв ${ }^{17}$.

Американский писатель часто в своих произведениях перечисляет многочисленные источники, в том числе и подлинные («История Атлантиды» и «Исчезнувшая Лемурия» Скотта-Эллиота). Автор тем самым играет смыслами и окончательно запутывает читателя.

Г.Ф. Лавкрафт описывает «Некрономикон» как «мрачный» и «отвратительный», который якобы был написан «безумным арабом», авторские эпитеты подменяют содержание источника. «Некрономикон» и «Пнакотические рукописи» лишь намекают на страшные тайны, но не раскрывают их смысл. Выдуманные автором источники порой отсылают к другим источникам тайного знания, которые чуть-чуть приоткрывают завесу над тайнами, но никогда не посвящают в них целиком. Подобная игра текстами, смыслами, источниками усиливает эффект присутствия сверхъестественного и заставляет читателя строить догадки. Ведь знать - значит быть уверенным в чем-то, а американскому писателю куда важнее удерживать читателя на границе «верить-не верить».

Таким образом, у Г.Ф. Лавкрафта не дом, полный старинных артефактов, как это было в готическом романе, становится проводником в сверхъестественное, а сама природа выступает артефактом, носителем темного знания. Черный Камень с таинственными иероглифами, посланный Эйкли рассказчику, имеет непосредственную связь с местными горными хребтами: ...я был абсолютно прав, ко-

17 Там же, с. 335. 
гда предположил, что те проклятые горы были гигантскими иероглифами ${ }^{18}$.

Носителями информации в произведениях Г.Ф. Лавкрафта выступают не только рукописные источники, но и вещественные артефакты, будь то статуэтки («Зов Ктулху», «Сны в ведьмином доме»), черный камень с иероглифами или пластинка с записью странных звуков («Шепоты во мраке»). Эти артефакты являются лишь фрагментами, мозаичными обрывками большой картины, они, как загадочные книги и тексты, лишь намекают на тайны, но никогда не поддаются окончательной дешифровке.

Известно, что язык науки строг и точен и не признает сослагательного наклонения, но многие научные факты и приспособления, описанные в тексте Г.Ф. Лавкрафтом, являются чистой воды авторским вымыслом, однако читатель не подвергает их сомнению. Способ перемещения космических существ во времени и пространстве с помощью подробно описанных замысловатых приспособлений принадлежит скорее области фантастики. Так, открытие самой дальней планеты солнечной системы Плутона дало возможность писателю включить его в свою систему вымысла:

Наши астрономы, мало о том подозревая, назвали ее чудовищно точно - «Плутон», что означает «подземное царство» или, если угодно, «ад». Разумеется, я-то знаю, что они открыли не что иное, как погруженный во мрак Юггот, - и всякий раз содрогаюсь, пытаясь докопаться до истины и понять, почему его ужасные обитатели пожелали заявить о существовании своего мира именно в это время. Я тщетно убеждаю себя в том, что это дьявольское отродье не начало постепенно переходить к новому плану действий, пагубному для Земли и ее исконных обитателей ${ }^{19}$.

В рассказе «По ту сторону сна» присутствие неземной сущности связано, например, с планетой в созвездии Персея Алголь, которую называют «Звездой-Дьяволом».

Таким образом, дом в художественном произведении - не просто архитектурный элемент, антураж, дом - это живое пространство, детерминирующее эмоциональное состояние героев, их духовные и душевные искания. Семантика слова «дом» очень обширна, поэтому художники слова неизбежно играют со смыслами, предлагая различные ракурсы интерпретации дома. Проза Г.Ф. Лавкрафта не является исклю-

18 Там же, с. 337.

19 Там же, с. 348. 
чением, художник по-своему осмысливает, трансформирует и расширяет топос дома. Если в готическом романе сосредоточием ужаса, как правило, выступал замок с его богатой историей, то ужас у Г.Ф. Лавкрафта вездесущ, он не просто сосредоточен в одной точке, он приходит из враждебного космического пространства, о котором так мало знает человек. В произведениях писателя происходит таким образом своеобразная ликвидация традиционного топоса дома. Готическая традиция и исключительное авторское мифопоэтическое мышление позволило писателю создать оригинальную модель современной ему жизни во взаимосвязи с национальной и общечеловеческой историей и глубоко осмыслить драматические коллизии современности как в философском, так и социокультурному контексте.

\section{LITERATURA}

King S., Plâska smerti, Moskva 2018 [Кинг С., Пляска смерти, Москва 2018].

Komlev N. G., Topos, top, [v:] Slovar' inostrannyh slov, [online], http://rus-yaz. niv.ru/doc/foreign-words-komlev/fc/slovar-210.htm\#zag-2276, [dostup:: 02.02.2021] [Комлев Н. Г., Топос, mon, [в:] Словарь иностранньх слов, [online], http://rus-yaz.niv.ru/doc/foreign-words-komlev/fc/slovar-210.htm\# zag-2276, (доступ: 02.02.2021)]

Kriklivece V., Hudožestvennyj mir V. Astaf'eva $i$ V. Koz'ko: specifika prostranstvenno-vremennoj organizacii, Vitebsk 2014 [Крикливец Е. В., Художественный мир В. Астафьева и В. Козько: специфика пространственно-временной организации, Витебск 2014].

Lavkraft G. F., Sny v ved'minom dome, [v:] Poln. sobr. soč., t. 1, Zataivšijsâ strah, Moskva 1992 [Лавкрафт Г. Ф., Сньл в ведьмином доме, [в:] Полн. собр. соч., т. 1, Затаившийся страх, Москва 1992].

Lavkraft G. F., Šepoty vo mrake, [v:] Lokon meduzy, Tol'âtti; Ekaterinburg 1993 [Лавкрафт Г. Ф., Шепоты во мраке, [в:] Локон медузы, Тольятти; Екатеринбург 1993].

Solov'eva N., V labirinte fantazii, [v:] Komnata s gobelenami: anglijskâ̂ gotičeskâ̂ proza, Moskva 1991 [Соловьева Н., В лабиринте фантазии, [в:] Комната с гобеленами: английская готическая проза, Москва 1991].

Cohn J., Miles T. H. Aesthetics and Psychoanalysis, «Modern Philology», Vol. 74, Feb. 1977. No. 3.

Holgate A., Aesthetics of Built Form, Oxford 1992.

House, [в:] Online etymology dictionary, [online], https://www.etymonline.com/ word/house, [доступ: 09.02.2021]. 
Punter D., The literature of terror: a history of Gothic fictions from 1765 to the present day, Vol. 2: The modern Gothic, London; New York, 1996.

Ringel F., I am providence: H. P. Lovecraft, [online], http://www.blackwellreference. com/public/tocnode?id=g9780470671870_chunk_g978047067187021, [доступ: 09.02.2021]

\author{
SUMMARY \\ SEMANTIC ASPECTS OF THE CONCEPT OF A HOUSE \\ IN GOTHIC LITERATURE AND ITS TRANSFORMATION \\ IN THE PROSE OF HOWARD PHILLIPS LOVECRAFT
}

The article examines semantic aspects of the concept of a house in Gothic literature and its transformation and comprehension by the American writer Howard Phillips Lovecraft. A house in literature is not just an architectural element, an entourage; it is a living space that determines the emotional state of characters, their spiritual and mental quest. The semantics of the word "house" is very extensive, therefore different writers (H.P. Lovecaft in particular) artfully play with meanings, offering their own original interpretations of a house.

Key words: prosa, house, topos, Gothic literature, transformation, Mythos, interpretations. 